\title{
Developing, Implementing, and Evaluating a No-Child-Left-Inside Pilot Program
}

\author{
Authors’ Version
}

\section{Recommended Citation:}

Brand, J. C., C. Radel, R. Brain, and J. Greene. 2014. Developing, implementing, and evaluating a No-Child-Left-Inside pilot program. Applied Environmental Education and Communication. 13(4): 261-268. DOI: 10.1080/1533015X.2014.983659.

Authors:

Jamie C. Brand

Department of Environment and Society, Utah State University, 5215 Old Main Hill, Logan, Utah, 84322-5215

USA; Email: jgcclark3@gmail.com

Claudia Radel (corresponding author)

Department of Environment and Society, Utah State University, 5215 Old Main Hill, Logan, Utah, 84322-5215

USA; Tel: 435-797-0516; Email: claudia.radel@usu.edu

Roslynn Brain

Department of Environment and Society, Moab Education Center, Utah State University, 125 W 200 S Moab, Utah 84532, USA; Tel: 435-259-7432; Email: roslynn.brain@usu.edu

Jack Greene

Cache Valley No Child Left Inside Coalition, jackisgreene@yahoo.com

Acknowledgements:

This work was supported by the Quinney College of Natural Resources and the Graduate School of Utah State University and the Cache Valley No Child Left Inside Coalition. 


\begin{abstract}
We describe experience with a pilot week-long, No-Child-Left-Inside (NCLI), outdoor program implemented in Cache Valley, Utah, in 2012. Through response analysis of a 'pre-then-post' children's survey and a parent-completed demographic survey, we assess program effectiveness in raising children's enthusiasm for nature-related behaviors and in reaching a target audience of all local families. The program reached many families with low participation in other conservation programs but failed to reach families from the growing Latino population. Participating children experienced increased excitement to spend more time outdoors exploring and learning, accomplishing NCLI goals of laying a groundwork for children's enhanced environmental literacy.
\end{abstract}

Keywords: nature, outdoor education, children, NCLI

\title{
Introduction
}

Buckets and Petrie dishes were laid out along the stream's shoreline with a magnifying glass for each participant. The second program ("Water Bugs") of No Child Left Inside (NCLI) Week had ended over thirty minutes earlier, yet forty children continued to wade in and out of the cold canyon stream as it flowed through Mack Memorial Park in Smithfield, Utah-the children wanted more. Unstructured time in nature (Louv, 2005) occurred organically, as children eagerly explored. One volunteer helped children look up each macro-invertebrate on the provided sheet. The children had to learn for themselves - wade into the water, turn over the rocks, catch the specimen, and place it in the Petrie dish. They were more than happy to comply.

During summer 2012, the First Annual Cache County NCLI Week was organized in affiliation with the local Cache County NCLI chapter. The basic philosophy underlying the national NCLI movement is, 'ensuring that every student achieves basic environmental literacy' (Chesapeake Bay Foundation, n.d.). In this day of technological advances and complex lives, many children have become disconnected from nature (Louv, 2005). This disconnect may correlate with obesity and attention/mental disorders in society (CDC, n.d.; Clay, 2001; Suzuki, 2013;). By encouraging our children to return to nature, we can increase awareness of their surroundings, develop their understanding of living things, and reconnect them to the earth. Ultimately, the end goal of the national NCLI movement and in particular, this week-long NCLI event, is to foster the development of future environmental stewards, recreationists, and ecologists for our planet.

The 2007 No Child Left Inside federal legislation was a response to the environmental education gap created by the 2001 No Child Left Behind Act (Chesapeake Bay Foundation, n.d.). The purpose of the 2001 Act was to refocus education on the fundamentals of math, science, and reading. Teachers emphasized information and ideas on which students would be tested, rather than focusing on the way children learn. Teachers no longer took students outside on fieldtrips; instead, they stayed inside to focus on math and reading fundamentals (Weilbacher, 2009). As a result, environmental education began to lose momentum and importance throughout the United States' core curriculum (Chesapeake Bay Foundation, n.d.).

The research behind a more recent resurgence of environmental education argues that not only does increased time in nature enhance connection to the natural environment, but it can also change attitudes and behaviors towards nature (Cheng \& Monroe, 2010; D’Amato \& Krasny, 
2011; Erdogan, 2011; Flett, Moore, Pfeiffer, Belonga, \& Navarre, 2010; Lewis, Mansfield, \& Baudains, 2010; Weilbacher, 2009). Increased time in nature also can raise test scores, increase self-efficacy, creativity, and cognition, and reduce stress and attention deficit disorder symptoms (Clay, 2001; Louv, 2005; Weilbacher, 2009). Environmental education can increase student engagement in science, improve student achievement in core subject areas, and help address 'nature deficit disorder' (Louv, 2005; Chesapeake Bay Foundation, n.d.).

Published evaluations of nature-based programs and outdoor education overwhelmingly focus on school groups (Cheng \& Monroe, 2012; Lewis et al., 2010; Erdogan, 2011), particularly fourth graders, or on outdoor camps, where older youth attend specific programs all week long (D’Amato \& Krasny, 2011). Few evaluations exist on community environmental education activities with differing participants at each event. Flett et al. (2011) have argued, 'there is a desperate need for more outreach programs to be developed, employed in real population (as opposed to conducting laboratory-based research) and evaluated.' This program evaluation responds to that call.

The 2012 Cache Valley NCLI Week Pilot Program was designed and implemented to assess the establishment of an annual event that would instill in children and their families a new or renewed excitement to learn about the local environment. Evaluation activities were carried out in parallel with the session activities. The results of this evaluation indicate the program achieved an increase in excitement and an intention to increase time spent outside, with a desire to learn more about nature. This article presents this pilot program and the findings from its evaluation.

\section{The Program}

Program educators were volunteers chosen from among local naturalists, who had the freedom to create their own sessions; however, the most successful sessions followed a lesson plan that began with a basic introduction or background to the topic, including definitions, i.e. aquatic macro-invertebrates, adaptation, and wetland, followed by hands-on experiences. For example, children gained a better understanding of habitat and adaptations by dressing up or seeing wildlife in their natural habitat (Kinder, 2012). Lesson plans connected to the Utah Core Curriculum (Standard 5, Objectives 2, 3, and 4) (Kinder, 2012). Program sessions were located throughout Cache Valley, at two city parks, one campground, and one natural area. Parks were chosen for their distributed location in the valley and their natural amenities (without manufactured playgrounds and with tree stands, natural grass areas, and streams).

Touching live animals, inspecting bug collections, and getting in a river to catch water macro-invertebrates with nets were just a few of the activities. Two sessions occurred each day, Monday through Friday, one in the morning and one in the evening. Each session topic, chosen based on available naturalists as well as the need for a broad subject range, was offered only once during the week. Topics (and activities) included: bugs, water bugs, Smokey Bear and campfire safety, nature journaling, birds and birding, bats, edible plants, nature crafts, fishing, rocks and basic geology, and snakes and reptiles. Four-hundred-eighty-one participants (this figure does not include children under the age of one) attended 11 programs. 


\section{Evaluation}

\section{Surveys}

The children's survey was based on a 'post-then-pre' evaluation method by Rockwell and Kohn (1989). This approach allowed children to take less time completing the survey and to evaluate their pre and post excitement more accurately after experiencing an activity. Following each activity, surveys were distributed to all families. Each child, with the assistance of an adult (usually a parent), was given a survey consisting of ten behavior-related questions. Answers were structured by a five-point Likert Scale ranging from one (not at all excited) to five (extremely excited) for engagement in each behavior, with the scale applied to each participant's personal assessment both 'before' and 'after,' as reported at the session's end. The first eight questions referred to the child's behavior towards and within nature. The last two questions referred to recycling efforts at home and in the community (see Table 1 for details and response frequencies for the ten questions). The recycling questions attempted to link participation in nature programs to more 'distant' environmental behaviors.

An additional survey was given to adults to collect demographic data on participants. This survey's objective was to better understand the makeup of program attendees and its comparison to the regional population. Parents were asked for their age, household salary, number of children attending, highest level of education completed, current marital status, religious affiliation, race or ethnicity, membership in any conservation groups, and how often they actively participated in conservation programs.

At the beginning of every session volunteers issued a request for adults to complete this 'demographic survey' and for children to complete a 'children's survey.' Surveys were then handed out at the conclusion of each session. Due to the younger ages of the children, volunteers encouraged parents to help their children answer the children's survey questions by reading aloud each question and response options, which could have been a source of bias. Other sources of response bias might include children listening to the answers of other children or possibly not understanding the meaning of 'neutral' and therefore not wanting to circle that answer.

Counts were taken of participants for each session, which resulted in some doublecounting for overall program attendance due to attendance of multiple sessions. The children's survey had 54 (17\%) respondents (63\% male and 35\% female) from the 324 child participants. Ages ranged from two to thirteen years old, with a mean age of $7.7(\mathrm{SD}=4.9)$. For the adults, 31 (20\%) out of 157 attending completed the demographic survey (81\% female and 19\% male). From observation, we know many families attended multiple programs, but only completed the adult survey once. In comparison, some children filled out more than one children's survey, as they attended multiple sessions. We did not remove these duplicates, as we were measuring change after each session.

\section{Effectiveness Reaching Target Population}

The demographic survey indicated that attendees were somewhat reflective of the local population (U.S. Census Bureau, 2010), but more particularly reflective of the target audience of families, as everyone who filled out a survey was married. However, despite close proximity to a state university with high rates of marriage and parenthood among students, few current student families participated. Of the surveyed adults, $90 \%$ were Caucasian, compared to $85 \%$ within 
Cache Valley (U.S. Census Bureau, 2010). Latinos represent 10\% of the Cache Valley region (U.S. Census Bureau, 2010), but had no representation throughout the week of programs. This finding is discussed further below.

Interesting results came from the question of how often these participating families partook in conservation programs (Figure 1). A majority (58\%) had never participated in any known program. The next highest response (23\%) was 'once a year'. The survey phrase, 'conservation program,' was not defined, and may have contributed to the high 'never' results. It is possible that changing the phrase to 'nature-related program' could have altered the response rates.

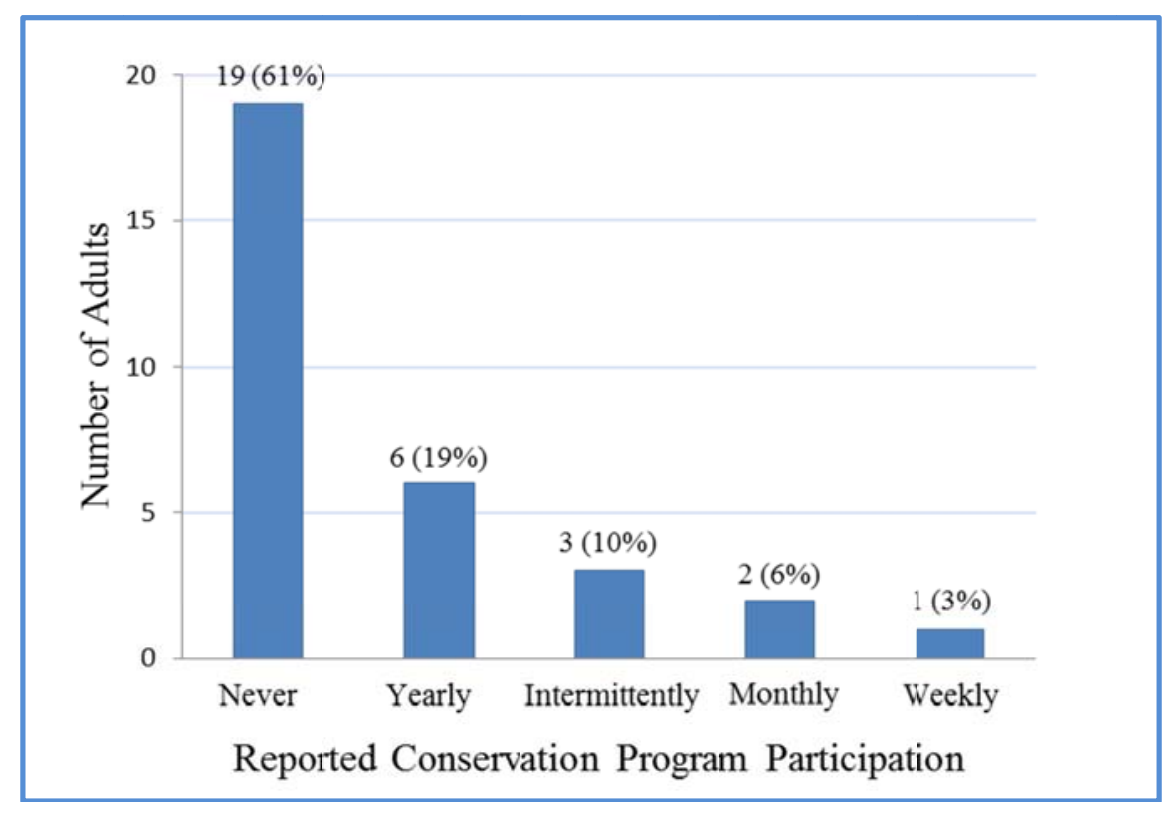

Figure 1: Reported participation level of surveyed adults in conservation programs.

\section{Effectiveness Increasing Children's Nature Enthusiasm}

Lewis et al. (2010) argue that environmental education is important in early childhood. During this critical time in life, children begin establishing behaviors and understanding of local environments. Data in Table 1 illustrates that the children expressed only moderate enthusiasm for nature prior to participating in the NCLI Week activities, expressed in the survey as 'excitement' to engage in particular actions. However, afterwards they expressed increased excitement to learn about and explore nature. 
Table 1: Children's Survey Response Frequencies $(\mathrm{N}=54)$

How excited are you...

\author{
Not at A little \\ all \\ excited \\ (1) \\ excited \\ (2)
}

1. To go exploring in your backyard

2. To go exploring in your neighborhood

3. To go exploring in your part of the state (northern Utah)

4. To visit a national forest, national park or state park

5. To learn more about wildlife, nature, or forests

6. To participate in a nature program in your town

7. To take a friend or sibling outside to explore

8. To teach a friend or sibling what you learned this week at one of our programs

9. To recycle at your house

10. To help educate your neighbors about recycling

Neutral

(3)

$\begin{array}{ccc}\begin{array}{c}\text { Very } \\ \text { excited }\end{array} & \begin{array}{c}\text { Ex- } \\ \text { tremely }\end{array} & \text { Missing } \\ (4) & \text { excited } & \end{array}$

(5)

\begin{tabular}{|c|c|c|c|c|c|c|}
\hline Before & 3 & 5 & 11 & 17 & 12 & 6 \\
\hline After & 1 & 1 & 2 & 8 & 39 & 3 \\
\hline Before & 1 & 5 & 13 & 12 & 16 & 7 \\
\hline After & 0 & 2 & 1 & 12 & 37 & 2 \\
\hline Before & 1 & 5 & 9 & 12 & 20 & 7 \\
\hline After & 0 & 1 & 3 & 11 & 37 & 2 \\
\hline Before & 0 & 2 & 11 & 13 & 23 & 5 \\
\hline After & 1 & 0 & 0 & 15 & 37 & 2 \\
\hline Before & 0 & 3 & 9 & 23 & 14 & 5 \\
\hline After & 2 & 0 & 2 & 10 & 39 & 1 \\
\hline Before & 0 & 5 & 12 & 13 & 19 & 5 \\
\hline After & 0 & 1 & 4 & 6 & 41 & 2 \\
\hline Before & 1 & 3 & 12 & 15 & 16 & 7 \\
\hline After & 1 & 1 & 2 & 10 & 37 & 3 \\
\hline Before & 1 & 8 & 12 & 14 & 11 & 8 \\
\hline After & 1 & 2 & 5 & 6 & 38 & 2 \\
\hline Before & 0 & 6 & 12 & 10 & 20 & 6 \\
\hline After & 0 & 3 & 6 & 11 & 32 & 2 \\
\hline Before & 6 & 8 & 15 & 7 & 12 & 6 \\
\hline After & 3 & 3 & 9 & 14 & 23 & 2 \\
\hline
\end{tabular}

For every survey question, reported excitement to engage in the behavior increased (statistically significant at $\mathrm{p}=0.00$ ) (Table 2 and Figure 2). Although the results are encouraging, we should remain cautious regarding the significance of the outcomes, as results pertain to immediate reported excitement and not longer-term excitement or behavior change. Many participants were extremely excited after touching snakes, breaking-up rocks, or catching insects. These children were in a state of enthusiasm and reported an extreme willingness to explore and experience nature. With no follow-up research possible within this pilot program evaluation, we do not know what the actual behavior of the children was by the end of the summer, whether 
excitement was sustained, whether or not the program increased actual time spent outdoors and in nature. Similar research within Cache Valley (Kinder, 2010) indicates fourth-grade students who attended Utah State University's Natural Resource Field Days in 2009 showed significant increase in knowledge two weeks after the event and were able to retain most information eight months after participation. Kinder's findings suggest that children who attended NCLI Week sessions should retain information learned throughout the summer months, and might therefore also retain excitement.

Table 2: Statistical Results of Paired T-Test for Children's Survey $(\mathrm{N}=54)$

How excited are you...

1. To go exploring in your backyard

2. To go exploring in your neighborhood

3. To go exploring in your part of the state (Northern Utah)

4. To visit a national forest, national park, or state park

5. To learn more about wildlife, nature, or forests

6. To participate in a nature program in your town

7. To take a friend or sibling outside to explore

8. To teach a friend or sibling what you learned this week at one of our programs

9. To recycle at your home

10. To help educate your neighbors about recycling

\begin{tabular}{ccc}
$\begin{array}{c}\text { Mean } \\
\text { response }\end{array}$ & SD & T-test results \\
\hline
\end{tabular}

3.62

4.63

1.16

$t=6.636, p=0.00$

After

3.79

0.82

Before

4.62

1.10

$\mathrm{t}=6.539, \mathrm{p}=0.00$

After

Before

3.96

0.72

After

4.63

1.12

$\mathrm{t}=4.959, \mathrm{p}=0.00$

Before

4.16

0.71

After

4.65

0.92

$\mathrm{t}=4.436, \mathrm{p}=0.00$

Before

3.98

4.60

0.71

After

3.94

4.67

0.85

$\mathrm{t}=6.155, \mathrm{p}=0.00$

Before

After

3.89

4.59

0.91

Before

After

3.57

4.50

1.03

$t=6.289, p=0.00$

Before

After

Before

3.92

4.38

0.71

1.03

$t=5.836, p=0.00$

After

Before

3.23

3.97

0.83

1.11

$t=7.508, p=0.00$

0.96

1.09

$t=4.485, p=0.00$

After 
Our evaluation measured changes in excitement levels from 'before' to 'after' the activity, with an average response increase of 0.7 points on the five-point scale (Figure 2). That is an average increase from 'very excited' to 'extremely excited,' which for children may not be a large expressed change, but may be enough to increase curiosity and willingness to explore outdoors, if only temporarily. Cheng and Monroe (2012) suggest that although excitement may be high after a program, behavior tends to change slowly and therefore one should not expect longer-term changes in attitudes and behavior after just a few nature-based sessions. The average change was not as high for the two questions pertaining to recycling. Contributing to these lower scores may have been the young age of participants, or not understanding the value of recycling. Recycling was never mentioned during any of the sessions, but 'helping the Earth' was highlighted by most presenters.

Survey findings are re-enforced by parent comments, 'my kids are so excited about this program;' 'This has been SO fun \& definitely got us outside and into places and topics we would not have otherwise gotten into;' 'This was a great week, very educational, great adventure for the kids to learn about their environment.'

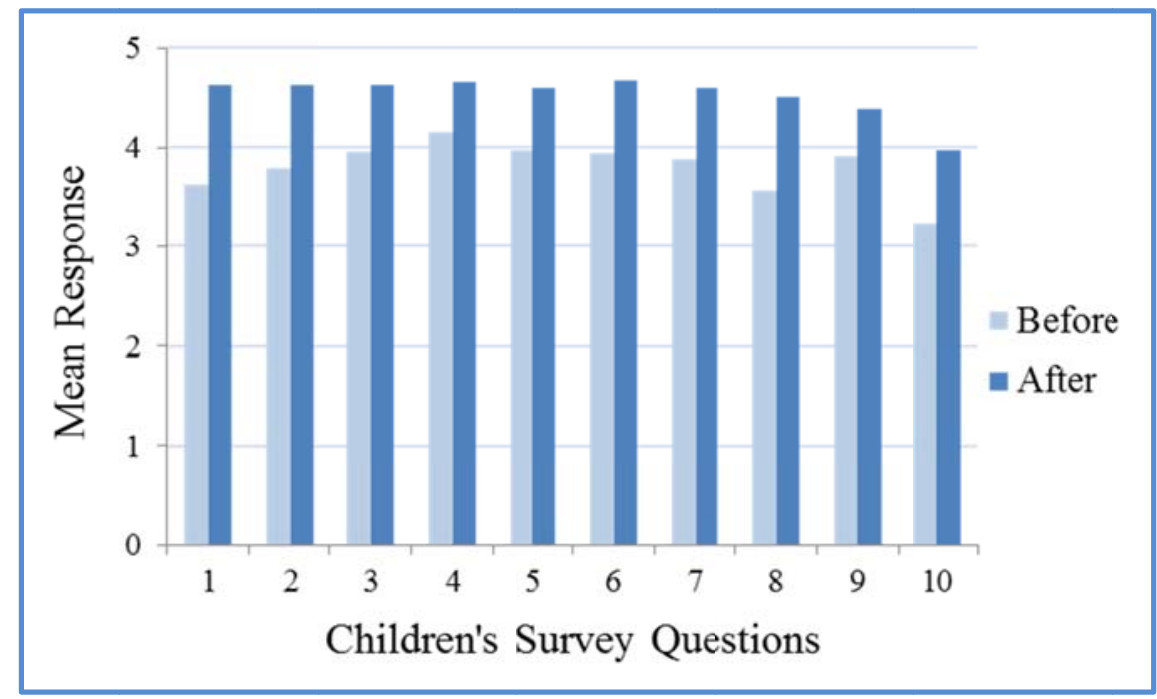

Figure 2: Children's reported before and after 'excitement.'

\section{Discussion and Recommendations for Practice}

The NCLI pilot program was successful in increasing enthusiasm in children towards nature. Enthusiasm might then translate into enjoyment of nature, where children learn to empathize with living creatures, develop interest in spending more time in nature, and increase mental and physical well-being within themselves (Cheng \& Monroe, 2012).

The goal of serving a cross-section of families in the community was less effectively met. We particularly note the absence of participation by Latinos. Latinos, the fastest growing ethnic group in America, are often "under-represented" in outdoor recreation and nature programs 
(Madsen, 2011; Madsen, Radel, \& Endter-Wada, 2014; Strife \& Downey, 2009; Van Velsor \& Nilon, 2007). Madsen (2011) has conducted research focused on the recreational decisions of Latinos in Cache Valley, determining that although Latinos use the Valley's city and state parks and recreate frequently with their families, they less often frequent national parks and lessdeveloped federal lands. A number of factors shape the decisions of Latinos, including unfamiliarity, cost, and language barriers (Madsen, 2011; Madsen, Radel, \& Endter-Wada, 2014; Strife \& Downey, 2009; Van Velsor \& Nilon, 2007). We recommend that fliers and schedules for future programs be bi-lingual, in an effort to address, at the very least, any language barriers. Additional strategies to explicitly welcome participation by the Latino community should be developed, including participation of Latino volunteer presenters or organizers. The lack of cost for participants can help overcome the financial barrier, while siting activities at local parks helps address access issues (Strife \& Downey, 2009). Nonetheless, ethnic and racial integration within the context of NCLI Week activities is likely to remain a challenge.

Many additional lessons learned from the pilot program experience suggest opportunities for future programs in Cache Valley and elsewhere. Because many of the participants attended multiple programs, the idea of a nature journal was discussed for the future. A nature journal would allow children to take notes or draw pictures of what they learned within each session in a fun and interactive way and could facilitate a broader reflection across sessions. It would also be a great place for participants to keep fliers, handouts, activity products, or photos mom and dad took to remember the experience and foment future explorations outside. Participants could also earn a 'naturalist badge,' similar to the National Park Service’s Junior Ranger Program, for attending multiple activities.

We found that children needed to take home a further activity to complete, apart from the craft or activity carried out during the session. This could include an activity page, kit (e.g. bat house to build after learning about regional bats), or species identification list. Take-home activities are tangible reminders that can extend learning.

We also learned that a crate filled with binoculars, Petrie trays, magnifying glasses, bug nets, and other tools kept at each session for participants to use as needed, was not only helpful but necessary. These tools were a great way for children to experience nature. Without them sessions would have been a less interactive learning experience.

This program gave families the opportunity to learn through hands-on, nature-based experiences. In today's world most families want to be active and spend time 'in nature together - as a family' (Flett et al., 2010) when the opportunity presents itself. Now is the time to take our children back outside to experience nature. Through these experiences children develop a deepened respect for the earth and for themselves, and they learn to care about living things (Wilson, 1997). The Cache Valley NCLI Week Pilot Program went beyond exposing children to nature, it involved them in discovery and exploration, further encouraging and enhancing the participants' excitement for and experience in the outside world around them. This excitement can serve as a foundation for environmental literacy and can become a stepping stone for future learning and exploration. 


\section{References}

Benbow, A. E., \& Camphire, G. (2008). No child left inside. The Science Teacher, September, 66-67.

CDC (Center for Disease Control). (n.d.). A growing problem. Retrieved from http://www.cdc.gov/obesity/childhood/problem.html.

Cheng, J., \& Monroe, M. C. (2012). Connection to nature: Children’s affective attitude toward nature. Environment and Behavior, 44, 31-49.

Chesapeake Bay Foundation. (n.d.). About the No Child Left Inside ${ }^{\circledR}$ Coalition. Retrieved from http://www.NCLICoalition.org.

Clay, R. A. (2001). Green is good for you. Monitor on Psychology, 32(4), 40.

D’Amato L. G., \& Krasny, M. E. (2011). Outdoor adventure education: Applying transformative learning theory to understanding instrumental learning and personal growth in environmental education. The Journal of Environmental Education, 42(4), 237-254.

Erdogan, M. (2011). The effects of ecology-based summer nature education program on primary school students' environmental knowledge, environmental affect and responsible environmental behavior. Educational Sciences: Theory \& Practice, 11, 2233-2237.

Flett, M. R., Moore, R. W., Pfeiffer, K. A., Belonga, J., \& Navarre, J. (2010). Connecting children and family with nature-based physical activity. American Journal of Health Education, 41(5), 292-300.

Kinder, T. (2012). Using short-term environmental education programs to increase student learning and elicit positive attitude change. MS Thesis, Utah State University.

Lewis, E., Mansfield, C., \& Baudains, C. (2010). Going on a turtle egg hunt and other adventures: Education for sustainability in early childhood. Australasian Journal of Early Childhood, 35(4), 95-100.

Louv, R. (2005). Last child in the woods: Saving our children from nature-deficit disorder. Chapel Hill, NC: Algonaquin Books of Chapel Hill.

Madsen, J., Radel, C., \& Endter-Wada, J. (2014). Justice and immigrant Latino recreation geography in Cache Valley, Utah. Journal of Leisure Research, 46(3), 291-312.

Madsen, J. J. (2011). Recreation patterns and decision drivers for Hispanics/Latinos in Cache Valley, Utah. MS Thesis, Utah State University.

Rockwell, S. K., \& Kohn, H. (1989). Post-then-pre evaluation. Journal of Extension [On-line], 27, 2. Retrieved from http://www.joe.org/joe/1989summer/a5.html. 
Skar, M., \& Krogh, E. (2009). Changes in children's nature-based experiences near home: From spontaneous play to adult-controlled, planned and organized activities. Children's Geographies, 7(3), 339-354.

Strife, S., \& Downey, L. (2009). Childhood development and access to nature: A new direction for environmental inequality research. Organization \& Environment, 22(1), 99-122.

Suzuki, D. (2003). Healthy kids need time in nature. Retrieved from http://www.childrenandnature.org.

Van Velsor, S. W., \& Nilon, C. H. (2007). A qualitative investigation of the urban AfricanAmerican and Latino adolescent experience with wildlife. Human Dimensions of Wildlife: An International Journal, 11(5), 359-370.

Weilbacher, M. (2009). The window into green. In M. Scherer (Ed.), Challenging the whole child: Reflections on best practices in learning, teaching, and leadership (38-44). Alexandria, VA: ASCD.

Wilson, R. (1997). The wonders of nature - honoring children's ways of knowing. Early Childhood News, 6(19). Retrieved from http://www.earlychildhoodnews.com.

U.S. Census Bureau. (2010). 2010 census. Retrieved from http://www.census.gov/2010census. 